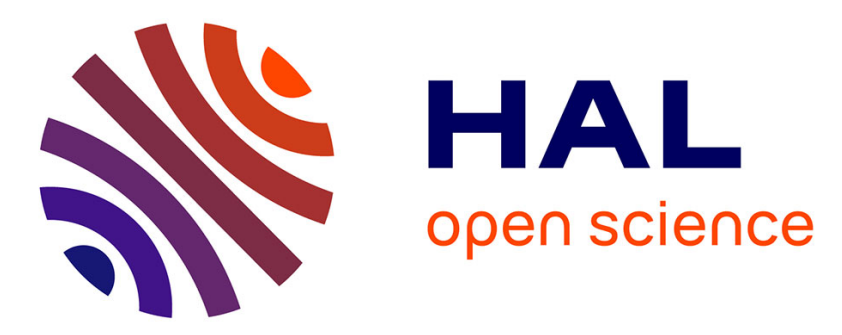

\title{
Modeling cortical spreading depression induced by the hyperactivity of interneurons
}

Mathieu Desroches, Olivier Faugeras, Martin Krupa, Massimo Mantegazza

\section{To cite this version:}

Mathieu Desroches, Olivier Faugeras, Martin Krupa, Massimo Mantegazza. Modeling cortical spreading depression induced by the hyperactivity of interneurons. Journal of Computational Neuroscience, 2019, 10.1007/s10827-019-00730-8 . hal-01520200

\section{HAL Id: hal-01520200 \\ https://hal.inria.fr/hal-01520200}

Submitted on 10 May 2017

HAL is a multi-disciplinary open access archive for the deposit and dissemination of scientific research documents, whether they are published or not. The documents may come from teaching and research institutions in France or abroad, or from public or private research centers.
L'archive ouverte pluridisciplinaire HAL, est destinée au dépôt et à la diffusion de documents scientifiques de niveau recherche, publiés ou non, émanant des établissements d'enseignement et de recherche français ou étrangers, des laboratoires publics ou privés. 


\title{
Modeling cortical spreading depression induced by the hyperactivity of interneurons
}

\author{
Mathieu Desroches ${ }^{2,4}$, Olivier Faugeras ${ }^{2,4}$, Martin Krupa $^{1}$, Massimo Mantegazza $^{3,4}$ \\ 1 Department of Applied Mathematics, University College Cork, Cork, Ireland. \\ E-mail: m.krupa@ucc.ie \\ 2 MathNeuro team, Inria Sophia Antipolis, 06902 Valbonne-Sophia Antipolis, France. \\ 3 CNRS UMR7275, Institute of Molecular and Cellular Pharmacology (IPMC), LabEx ICST, 06560 \\ Valbonne-Sophia Antipolis, France. \\ 4 Université Côte d'Azur, 06560 Valbonne-Sophia Antipolis, France.
}

\begin{abstract}
Cortical spreading depression (CSD) is a wave of transient intense neuronal firing leading to a long lasting depolarization block of neuronal activity. It is a proposed pathological mechanism of migraine with aura. Some molecular/cellular mechanisms of migraine with aura and of CSD have been identified studying a rare mendelian form: familial hemiplegic migraine (FHM). FHM type 1 \& 2 are caused by mutations of the $\mathrm{CaV} 2.1 \mathrm{Ca}^{2+}$ channel and the glial $\mathrm{Na}^{+} / \mathrm{K}^{+}$pump, respectively, leading to facilitation of CSD in mouse models mainly because of increased glutamatergic transmission/extracellular glutamate build-up. FHM type 3 mutations of the SCN1A gene, coding for the voltage gated sodium channel $\mathrm{NaV1.1}$, cause gain of function of the channel and hyperexcitability of GABAergic interneurons. This leads to the counterintuitive hypothesis that intense firing of interneurons can cause CSD ignition. To test this hypothesis in silico, we developed a computational model of an E-I pair (a pyramidal cell and an interneuron), in which the coupling between the cells in not just synaptic, but takes into account also the effects of the accumulation of extracellular potassium caused by the activity of the neurons and of the synapses. In the context of this model, we show that the intense firing of the interneuron can lead to CSD. We have investigated the effect of various biophysical parameters on the transition to CSD, including the levels of glutamate or GABA, frequency of the interneuron firing and the efficacy of the KCC2 co-transporter. The key element for CSD ignition in our model was the frequency of interneuron firing and the related accumulation of extracellular potassium, which induced a depolarization block of the pyramidal cell. Our model can be used to study other types of activities in microcircuits and of couplings between excitatory and inhibitory neurons.
\end{abstract}

\section{Introduction}

Cortical spreading depression (CSD) is a wave of transient intense neuronal firing leading to a long lasting depolarization block of neuronal activity, which initiates focally and then slowly propagates in the cerebral cortex 27]. Long lasting spreading depolarizations of cortical circuits are involved in different pathophysiological conditions [1]. Metabolically compromised injured brain tissue (in stroke, trauma 
and subarachnoid hemorrhage) generates anoxic spreading depolarizations that lead to cell death or long-lasting damage. Differently, CSD generated in normoxic tissue does not cause neuronal death, is reversible and is a proposed pathological mechanism of migraine with aura 13.20 27. In this condition, CSD causes transient neurological symptoms before the headache (the aura phase), and it has been proposed that the CSD-depended stimulation of trigeminal nociceptor nerve fibers innervating the blood vessels of the meninges causes the headache. CSD is characterized by a massive redistribution of ions across cell membranes, which modify ionic concentration gradients leading to depolarization [27.

Some molecular/cellular mechanisms of CSD and migraine have been identified studying a rare form of genetic mendelian with aura, characterized by hemiparesis during the attacks: familial hemiplegic migraine (FHM). FHM type 1 (FHM-1) is caused by gain of function mutations of the alpha1 subunit of the CaV2.1 P/Q type $\mathrm{Ca}^{2+}$ channel (CACNA1A gene) 26]; FHM-2 is caused by loss-of-function mutations of the alpha2 subunit of the glial $\mathrm{Na}^{+} / \mathrm{K}^{+}$pump (ATP1A2 gene) 8. Facilitation of CSD has been reported in knock-in FHM-1 and FHM-2 mouse models [21,23. Moreover, it has been shown that FHM mutations in these mouse models cause increased glutamatergic transmission and extracellular glutamate accumulation [4, 30,34], consistently with a similar overall mechanism.

FHM-3 is caused by mutations of the NaV1.1 sodium channel (SCN1A gene) 9 but the pathological mechanism of these mutations is less well understood 33. NaV1.1 is particularly important for generating GABAergic neurons' excitability (the neurons that classically have an inhibitory role in cortical circuits), and its mutations have been identified also in epileptic patients 15, 38. Epileptogenic NaV1.1 mutations cause loss-of-function of the channel with consequent decreased excitability of GABAergic neurons, reduced inhibition and hyperexcitability of cortical networks $16,17,25,38$. Conversely, although initially loss of function has been reported also for FHM-3 NaV1.1 mutations [18], more recent works provide evidence that these mutations cause instead a gain-of-function of the channel leading to hyperexcitability of GABAergic neurons in transfected cells in culture 5 -7. These results point to a different, counterintuitive mechanism in comparison to FHM-1 and FHM-2 mutations. In fact, it is not clear how increased activity of GABAergic neurons could trigger CSD, because it should reduce excitability of neuronal networks.

Three mechanisms (possibly acting in parallel) have been hypothesized for the ignition of CSD upon hyperexcitability of GABAergic interneurons [5 7]: 1) the extracellular potassium build-up generated by the potassium currents activated by the spiking of the interneurons, 2) the potassium build-up generated by the KCC2 co-transporter of the post synaptic pyramidal neurons, and 3) excitatory actions of GABAergic transmission. The first mechanism is expected during high frequency firing of the (inter)neurons. The second one has been reported in conditions of intense GABAergic synaptic transmission, because the function of $\mathrm{KCC} 2$ is to co-transport chloride and potassium for maintaining a low intracellular chloride concentration in the pyramidal cells, leading to an efflux of potassium $10,19,35$. The third one can come into play when the homeostatic mechanisms that keep the intracellular chloride concentration low (in particular $\mathrm{KCC} 2$ ) reach their limits, leading to a transient partial dissipation of the chloride gradient and to depolarizing excitatory actions upon activation of the GABA-A receptor 22]. These mechanisms could increase the excitability of pyramidal neurons possibly leading to CSD.

We present here a modeling study undertaken to test the hypothesis that CSD can be ignited by intense firing of interneurons and to identify the mechanism of ignition in our model. We implemented a simple model of a pair of interconnected neurons, a pyramidal glutamatergic neuron (excitatory, E) and a GABAergic interneuron (inhibitory, I) (Figure 1). We investigated the effect of different levels of excitability of the interneuron on the connected pyramidal neuron, considering the depolarization block of the pyramidal neuron as the initiation of CSD. The interaction between the two cells consists of a GABAergic synapse from the interneuron onto the pyramidal cell, and a glutamatergic synapse from the pyramidal cell onto the interneuron. In addition we included a glutamatergic autapse (excitatory self 
coupling from the pyramidal cell to itself), in order to take into account the role of the glutamatergic input on the pyramidal cell. We developed our model extending that of Wei et al. [36], who used a Hodgkin-Huxley type neuron model to study the neuronal dynamics underlying the generation of spikes, epileptic activity and CSD. The same authors subsequently used this model for investigating the role of cell volume in the transitions between these phenomena [32]. In our model the pyramidal cell is an adapted version of the neuron of [36, whereas for the interneuron we have used the Wang-Buzsaki model [37].

Our findings show that CSD can be ignited in our model as a result of the intense firing of the interneuron, whereas in the absence of firing of the interneuron the pyramidal cell does not undergo CSD, and with moderate firing frequency of the interneuron the pyramidal neuron is inhibited. Our results indicate that the extracellular potassium build-up generated by the firing of the interneuron is the key factor for the initiation of CSD in our model.

\section{Methods}

The model (Figure 1) consists of an excitatory-inhibitory pair, where the former is a pyramidal cell and the latter an interneuron, with GABAergic synaptic connection from I to E, a glutamatergic synapse from $\mathrm{E}$ to I, and an autapse from E to itself. It includes the action of the KCC2 and of the NKCC1 co-transporters in the pyramidal cell and the extracellular diffusion of potassium (a simple diffusion equation for taking into account the diffusion in the extracellular space and spatial buffering by glia). Our model is based on the model of [36, see also 32 .

\section{Pyramidal cell}

The spiking of the pyramidal cell is generated by a Traub-Miles (TM) model of a (hippocampal) pyramidal cell, given by the following system:

$$
\begin{aligned}
C \frac{d V}{d t} & =J_{E}-I_{L}-I_{K}-I_{N a}-I_{N a p}-I_{\mathrm{AHP}} \\
\frac{d n}{d t} & =\phi\left(\alpha_{n}(v)(1-n)-\beta_{n}(v) n\right) \\
\frac{d h}{d t} & =\phi\left(\alpha_{h}(v)(1-h)-\beta_{h}(v) h\right) \\
\frac{d C a_{2}}{d t} & =-\varepsilon g_{C a} m_{\infty, 1}\left(V-E_{C a}\right)-\frac{C a_{2}}{\tau_{C a}}
\end{aligned}
$$

with $J_{E}$ representing the external drive (baseline current input), $I_{L}$ the leak current, $I_{N a}$ and $I_{K}$ the usual spike generating sodium and potassium currents, and $I_{N a p}$ the persistent slowly inactivating sodium current. Finally, $I_{A H P}$ is a calcium activated potassium current, a so-called adaptation current. Thus, system (1) is obtained from a simplified version of the Traub-Miles model 31] by adding the adaptation current $I_{A H P}$ and the persistent sodium current $I_{N a p}$.

The currents appearing in the RHS of (1) were defined as follows: $I_{L}=g_{L}\left(v-E_{L}\right), I_{K}=g_{K} n^{4}\left(v-E_{K}\right)$, $I_{N a}=g_{N a} m^{3} h\left(v-E_{N a}\right), I_{N a p}=g_{p} m^{3}\left(v-E_{N a}\right)$ and $I_{\mathrm{AHP}}=g_{\mathrm{AHP}} \frac{\mathrm{Ca}_{2}}{\mathrm{Ca}_{2}+1}\left(V-E_{K}\right)$. The functions were defined as follows: $m_{\infty}(v)=\alpha_{m}(v) /\left(\alpha_{m}(v)+\beta_{m}(v)\right), \alpha_{m}(v)=0.32(v+54) /\left(1-\exp ^{-(v+54) / 4}\right), \beta_{m}(v)=$ $0.28(v+27) /\left(\exp ^{(v+27) / 5}-1\right), \alpha_{h}(v)=0.128 \exp ^{-(v+50) / 18}, \beta_{h}(v)=4 /\left(1+\exp ^{-(v+27) / 5}\right), \alpha_{n}(v)=$ $0.032(v+52) /\left(1-\exp ^{-(v+52) / 5}\right) m_{\infty, 1}=1 /(1+\exp (-(V+25) / 2.5))$ and $\beta_{n}(v)=0.5 \exp ^{-(v+57) / 40}$. 


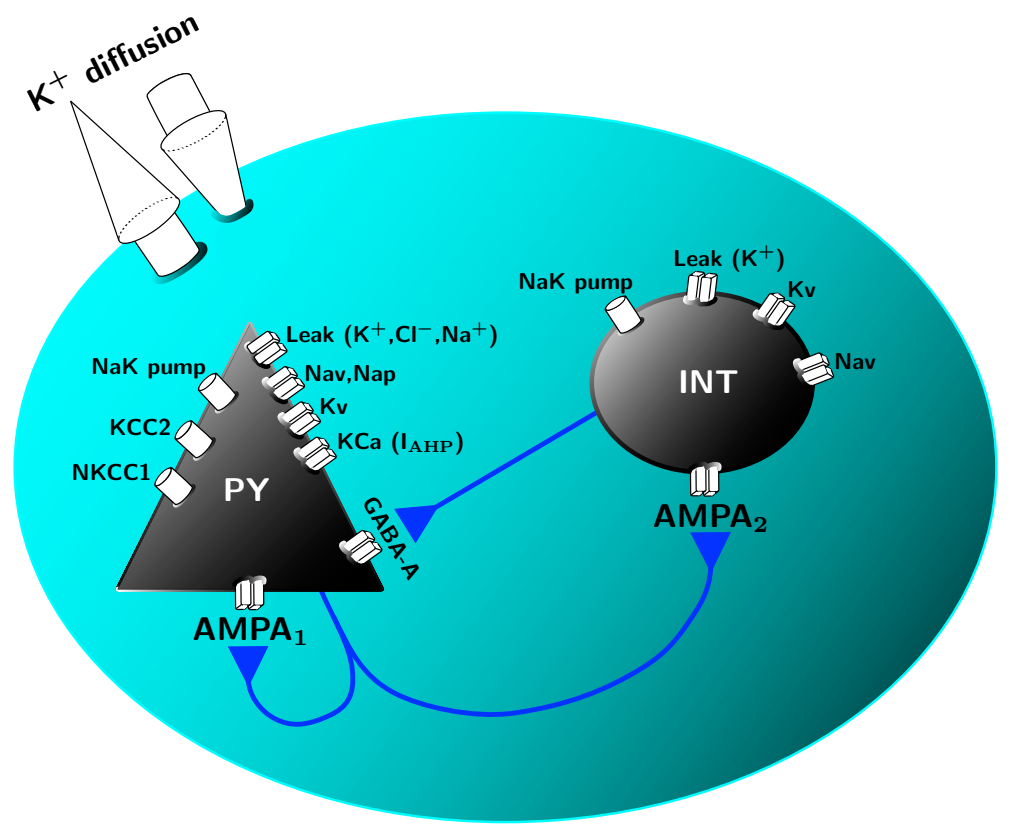

Figure 1: Diagram of the model. The model implements a pair of interconnected neurons, a pyramidal glutamatergic neuron (excitatory, E) and a GABAergic interneuron (inhibitory, I). The interaction between the two cells consists of a GABAergic synapse $\left(I_{\mathrm{GABA}}\right)$ from the interneuron onto the pyramidal cell, a glutamatergic synapse from the pyramidal cell onto the interneuron (AMPA1), and a glutamatergic autapse (excitatory self coupling from the pyramidal cell to itself, AMPA2), in order to take into account the role of a glutamatergic input on the pyramidal cell. It includes the action of the $\mathrm{KCC} 2$ and of the $\mathrm{NKCC} 1$ co-transporters in the pyramidal cell and the extracellular diffusion of potassium (for taking into account the diffusion in the extracellular space and spatial buffering by glia).

The parameter settings are as follows: $g_{N a}=100 \mathrm{mS} / \mathrm{cm}^{2}, E_{N a}=48 \mathrm{mV}, g_{p}=0.5 \mathrm{mS} / \mathrm{cm}^{2}, g_{K}=$ $80 \mathrm{mS} / \mathrm{cm}^{2}$ and $\phi=1, g_{\mathrm{AHP}}=1 \mathrm{mS} / \mathrm{cm}^{2}, E_{C a}=120 \mathrm{mV}, g_{C a}=1 \mathrm{mS} / \mathrm{cm}^{2}, \tau_{C a}=80 \mathrm{~ms}$ and $\varepsilon=$ $0.002(\mathrm{~ms} \mu \mathrm{A})^{-1} \mathrm{~cm}^{2}$. We use different values of $J_{E}$, ranging from $3.4 \mathrm{~mA}$ to $4 \mathrm{~mA}$.

The reversal potentials $E_{N a}, E_{K}$ and $E_{C l}$ (the latter determining the $I_{\mathrm{GABA}}$ reversal potential) in computational models are typically set to be constant. In our model, they are slowly varying variables, as their variation is the cause of spreading depression. The parameter $E_{L}$ is derived from $E_{K}, E_{C l}$ and $E_{N a}$ (this will be discussed in detail below). 


\section{Dynamic sodium, potassium and chloride concentrations}

The evolution equations for the ionic concentrations, measured in $m M=m o l / l$, are as follows:

$$
\begin{aligned}
& \frac{d[K]_{o}}{d t}=\frac{1}{\tau}\left(\gamma \beta\left(I_{K}+I_{\mathrm{AHP}}+I_{K, L}-2 I_{\mathrm{pump}}\right)+\beta\left(I_{\mathrm{KCC}}+I_{\mathrm{NKCC}}\right)\right.\left.\quad-I_{\mathrm{diff}}+\gamma_{i} \beta I_{K, i}\right) \\
& \frac{d[N a]_{i}}{d t}=\frac{1}{\tau}\left(-\gamma\left(I_{N a}+I_{N a p}+I_{N a, L}+3 I_{\mathrm{pump}}\right)-I_{\mathrm{NKCC}}\right) \\
& \frac{d[C l]_{i}}{d t}=\frac{1}{\tau}\left(\gamma\left(I_{\mathrm{GABA}}+I_{C l, L}\right)-I_{\mathrm{KCC}}-2 I_{\mathrm{NKCC}}\right) .
\end{aligned}
$$

Here $I_{K}, I_{\mathrm{AHP}}$ and $I_{N a}$ are as introduced above and $I_{K, L}, I_{N a, L}$ and $I_{C l, L}$ are the individual leak currents. We will return to the leak current and its components later. We now describe the remaining terms and parameters contributing to system (2).

\section{Co-transporters}

$I_{\mathrm{KCC}}$ is the flux through the $K-C l$ co-transporter KCC2 (which extrudes potassium and chloride), as used in [36], given by:

$$
I_{\mathrm{KCC}}=\rho_{\mathrm{KCC}} \log \left(\frac{[K]_{i}[C l]_{i}}{[K]_{o}[C l]_{o}}\right),
$$

and $I_{\mathrm{NKCC}}$ is the flux through the $\mathrm{Na}-\mathrm{K}-\mathrm{Cl}$ co-transporter NKCC, which transports sodium, potassium and chloride into the cells, given by:

$$
I_{\mathrm{NKCC}}=\rho_{\mathrm{NKCC}} f\left([K]_{o}\right)\left(\log \left(\frac{[K]_{i}[C l]_{i}}{[K]_{o}[C l]_{o}}\right)+\log \left(\frac{[N a]_{i}[C l]_{i}}{[N a]_{o}[C l]_{o}}\right)\right)
$$

with

$$
f\left([K]_{o}\right)=\frac{1}{1+\exp \left(16-[K]_{o}\right)}
$$

The parameter settings are:

$$
\rho_{\mathrm{KCC}}=0.3 \mathrm{mM} / \mathrm{s} \text { and } \rho_{\mathrm{NKCC}}=0.1 \mathrm{mM} / \mathrm{s} .
$$

\section{Sodium/potassium pump}

The sodium potassium ATPase is the main mechanism restoring the ion concentrations to their steady state values. The current through the pump is modelled as follows:

$$
I_{\text {pump }}=\rho_{\text {pump }} \frac{1}{\gamma} \frac{1}{1+\exp \left(\left(N a_{\text {rev }}-[N a]_{i}\right) / 3\right)} \frac{1}{1+\exp \left(K_{\mathrm{rev}}-[K]_{o}\right)},
$$

where $\rho_{\text {pump }}=0.2 \mathrm{mM} / \mathrm{s}, N a_{\mathrm{rev}}=22 \mathrm{mM}$ and $K_{\mathrm{rev}}=3.5 \mathrm{mM}$. 


\section{Coupling currents from the interneuron}

$I_{\mathrm{GABA}}$ is the chloride current generated by the GABA-A receptors of the inhibitory synapse; we will present it in more detail in the section on synaptic currents. $I_{K_{i}}$ is the potassium current of the interneuron, and it contributes to the dynamics of $[K]_{o}$, see $(2)$, providing a form of coupling from the interneuron to the pyramidal cell, in addition to the GABAergic synapse.

\section{The conversion factors $\beta, \gamma, \tau$ and $\gamma_{i}$}

The parameter $\beta$ is the ratio of the intracellular to the extracellular space and is set to $\beta=4$, see $[29$. The parameters $\gamma$ and $\gamma_{i}$, whose units are $\mathrm{mol} /(C \cdot \mathrm{cm})$, are conversion factors from current density to the flux of ionic concentration, with $\gamma$ corresponding to the pyramidal cell and $\gamma_{i}$ to the interneuron. The parameter $\gamma$ is given by $\gamma=S /(F \cdot \mathrm{Vol})$, where $S$ is the surface of the cell, Vol its volume, and $F$ is the Faraday constant, with $\gamma$ corresponding to the pyramidal cell, with

$$
\mathrm{Vol}=1.4368 \cdot 10^{-9} \mathrm{~cm}^{3}, \quad S=4 \pi\left(\frac{3 \mathrm{Vol}}{4 \pi}\right)^{2 / 3} .
$$

The parameter $\gamma_{i}$ plays a similar role for the potassium current of the interneuron, that is it converts this current into an ionic flux. In our simulations we used $\gamma_{i}=0.75 \gamma$. The parameters $\gamma / \tau$ and $\gamma_{i} / \tau$, where $\tau=1000$, guarantee that the units of the RHS of $(2)$ are $m M / m s$.

\section{Potassium sink}

The expression modelling the diffusion of potassium in the extracellular space is

$$
I_{\text {diff }}=\varepsilon_{K}\left([K]_{o}-K_{\text {bath }}\right),
$$

with $\varepsilon_{K}=0.4 \mathrm{~s}^{-1}$ and $K_{\text {bath }}=3.5 \mathrm{mM}$. This simple expression accounts for the removal of $[K]_{o}$. It models diffusion in the extracellular space but also (in an extremely simplified way) the spatial buffering performed by the glia.

\section{Dynamics of the complementary ion concentrations}

In addition we include the dynamics of $[K]_{i}$, given by

$$
\frac{d[K]_{i}}{d t}=-\frac{1}{\tau} \gamma\left(I_{K}+I_{K, L}-2 I_{\text {pump }}+I_{K C C}+I_{N K C C}\right)
$$

as well as require that

$$
\frac{d}{d t}\left(\beta[N a]_{i}+[N a]_{o}\right)=\frac{d}{d t}\left(\beta[C l]_{i}+[C l]_{o}\right)=0 .
$$

Hence $[\mathrm{Na}]_{o}$ and $[\mathrm{Cl}]_{i}$ also vary dynamically. 


\section{The reversal potentials}

The reversal potentials correspond to the Nernst equilibrium, given by

$$
\begin{aligned}
& E_{K}=-\left(\frac{R T}{F}\right) \log \left(\frac{[K]_{o}}{[K]_{i}}\right) \\
& E_{N a}=-\left(\frac{R T}{F}\right) \log \left(\frac{[N a]_{o}}{[N a]_{i}}\right) \\
& E_{C l}=\left(\frac{R T}{F}\right) \log \left(\frac{[C l]_{o}}{[C l]_{i}}\right) .
\end{aligned}
$$

\section{Leak current}

The leak current $I_{L}$ is the sum of a potassium leak current, a chloride leak current and a sodium leak current, that is:

$$
I_{L}=g_{N a, L}\left(v-E_{N a}\right)+g_{K, L}\left(v-E_{K}\right)+g_{C l, L}\left(v-E_{C l}\right),
$$

or, equivalently,

$$
I_{L}=g_{L}\left(v-E_{L}\right),
$$

with

$$
g_{L}=\left(g_{N a, L}+g_{K, L}+g_{C l, L}\right) \quad \text { and } E_{L}=\frac{1}{g_{L}}\left(g_{N a, L} E_{N a}+g_{K, L} E_{K}+g_{C l, L} E_{C l}\right) .
$$

We have used in our simulations:

$$
g_{C l, L}=0.015, \quad g_{K, L}=0.05, \quad g_{N a, L}=0.0015 .
$$

\section{Interneuron}

The Wang-Buzsaki model of a fast spiking interneuron (PV+ basket cell) 37] is given by system (1) with

$$
\begin{aligned}
\alpha_{m} & =0.1(v+35.0) /(1.0-\exp (-(v+35.0) / 10.0)), \\
\beta_{m} & =4.0 \exp (-(v+60.0) / 18.0), \\
\alpha_{h} & =0.07 \exp (-(v+58.0) / 20.0), \\
\beta_{h} & =1.0 /(1.0+\exp (-(v+28.0) / 10.0)), \\
\alpha_{n} & =0.01(v+34.0) /(1.0-\exp (-(v+34.0) / 10.0)), \\
\beta_{n} & =0.125 \exp (-(v+44.0) / 80.0), \\
m_{\infty} & =a_{m} /\left(a_{m}+b_{m}\right)
\end{aligned}
$$

and the parameters: $g_{N a}=35 \mathrm{mS} / \mathrm{cm}^{2}, E_{N a}=55 \mathrm{mV}, \phi=5, g_{L}=0.1 \mathrm{mS} / \mathrm{cm}^{2}, E_{L}=-65 \mathrm{mV}$, $g_{K}=9 \mathrm{mS} / \mathrm{cm}^{2}$, and $E_{K}=-90 \mathrm{mV}$. The external drive to the interneuron (baseline current input) is denoted by $J_{I}$ and is varied between $0.6 \mathrm{~mA}$ and $1.2 \mathrm{~mA}$, with the frequency varying from approximately $40 \mathrm{~Hz}$ to approximately $80 \mathrm{~Hz}$. 


\section{Synaptic currents}

We modeled the synaptic coupling from the interneuron to the pyramidal cell, with the synaptic current:

$$
I_{\mathrm{GABA}}=g_{\mathrm{GABA}} s\left(V-E_{C l}\right) .
$$

The synaptic variable $s$ is set to 1 following a spike of the interneuron and subsequently obeys the equation:

$$
\frac{d s}{d t}=-\frac{1}{\tau_{\mathrm{GABA}}} s
$$

with $\tau_{\mathrm{GABA}}=9 \mathrm{~ms}$. We have included an (AMPA) excitatory connection from the pyramidal cell to itself (maximal conductance $g_{\mathrm{AMPA} 1}$ ) as well as an (AMPA) excitatory connection from the pyramidal cell onto the interneuron (maximal conductance $\left.g_{\mathrm{AMPA} 2}\right)$, with associated currents $I_{\mathrm{AMPA}, \mathrm{E}}=g_{\mathrm{AMPA} 1} \tilde{s}_{E}\left(V_{E}-\right.$ $\left.E_{\mathrm{AMPA}}\right)$ and $I_{\mathrm{AMPA}, \mathrm{I}}=g_{\mathrm{AMPA} 2} \tilde{s}_{I}\left(V_{I}-E_{\mathrm{AMPA}}\right)$, respectively. The synaptic variables $\tilde{s}_{E}$ and $\tilde{s}_{I}$ follow a similar evolution equation as $s$, with a time constant $\tau_{\mathrm{AMPA}}=3 \mathrm{~ms}$. The values of $g_{\mathrm{AMPA} 1}$ and $g_{\mathrm{AMPA} 2}$ are set to $0.1 \mathrm{mS} / \mathrm{cm}^{2}$ unless stated otherwise.

\section{Final voltage equation}

The final form of the current balance in the pyramidal cell, with the addition of the synaptic current and the pump current (the balance of currents through $\mathrm{KCC} 2$ equals 0 ) is

$$
C \frac{d V}{d t}=J_{E}-\left(I_{L}+I_{K}+I_{N a}+I_{N a p}+I_{\mathrm{GABA}}+I_{\mathrm{pump}}+I_{\mathrm{AMPA}}+I_{\mathrm{AHP}}\right) .
$$

The simulations were carried out on a MacBookPro laptop using the software package XPPAUT [12.

\section{Results}

\section{Interneuron firing can cause spreading depression}

As mentioned earlier, the main goal of this work is to test the hypothesis stating that intense firing of interneurons can initiate spreading depression. In our first simulation we chose parameter settings that gave tonic spiking of the pyramical cell (between 11 and 17 spikes/s) in the absence of an active coupling with the interneuron (Fig. 22). With an active coupling to the interneuron and parameter settings leading to a moderate firing frequency (approximately $40 \mathrm{~Hz}$ ), the firing frequency of the pyramidal neuron was constantly reduced in the initial 10s of the simulation (Fig. 2(a)-(b)) and, for the rest of the simulation, it remained lower or equal to the firing frequency of the pyramidal neuron observed in the absence of an active coupling with the interneuron $\left(\gamma_{i}=g_{\mathrm{GABA}}=0\right)$ (Fig. 2(c)).

Fig. 3 shows the effect of varying the firing frequency of the interneuron. An increase of the firing frequency of the interneuron to about $60 \mathrm{~Hz}$ gave rise to an initial inhibitory effect, which completely abolished the spiking of the pyramidal cell (Fig. 3(c)), followed by a period of hyperexcitability (between 17.5 and $22.5 \mathrm{~s}$ after the beginning of the simulation), in which the frequency of the pyramidal cell became significantly higher (Fig. 3. (c)) than in the absence of the interneuron (see Fig. 3(a)). Notably, when the interneuron was set to spike at about $40 \mathrm{~Hz}$, the initial inhibitory effect that completely abolished the spiking of the pyramidal cell was not observed (Fig. 3(b)). Fig. 3(d)-(f) displays a more detailed analysis of the effect of the interneuron on the firing of the pyramidal cells in the time window $17.5-22.5 \mathrm{~s}$ after 
(a)
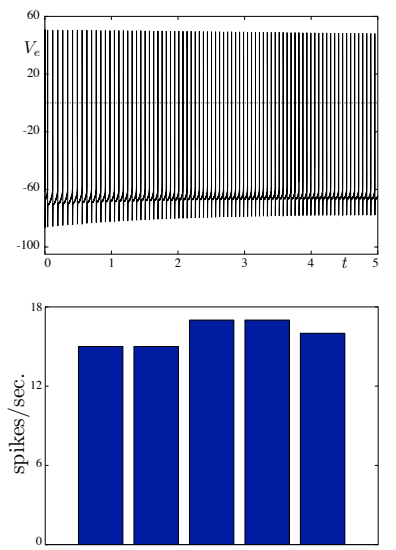
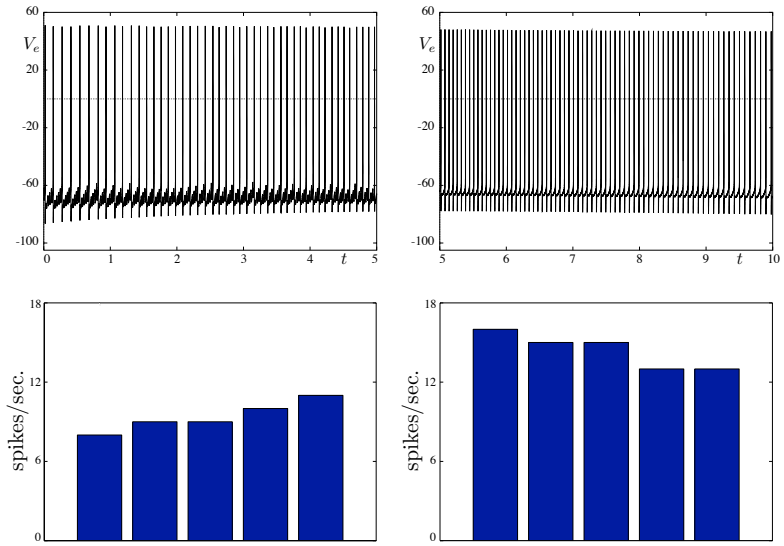

(c)
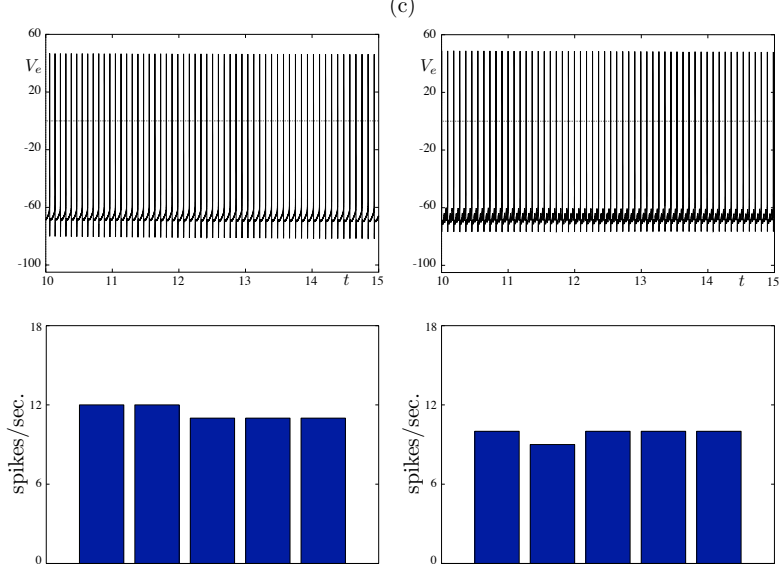

(b)
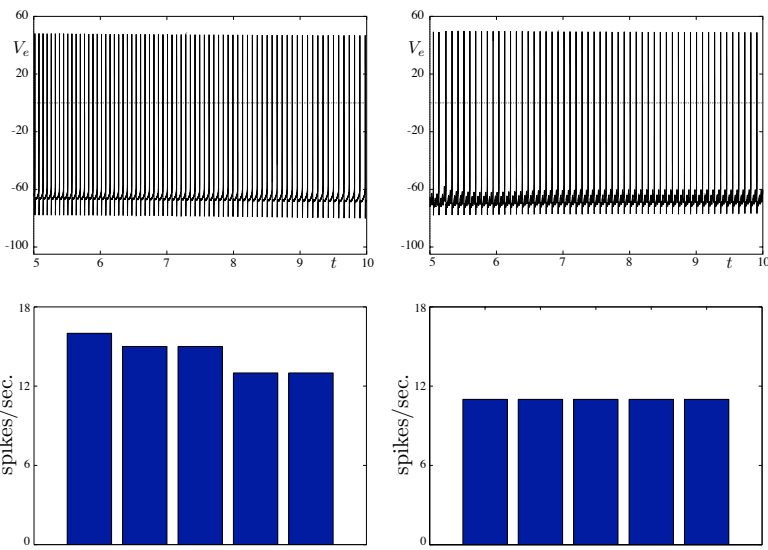

Figure 2: Inhibitory effect of the interneuron spiking at moderate frequency. When the interneuron is set to fire at about $40 \mathrm{~Hz}\left(J_{i}=0.6\right)$, it exerts an inhibitory action on the firing of the pyramidal cell. Panel (a) shows, in the top left corner the first $5 \mathrm{~s}$ of the firing of the pyramidal cell (driven by $J_{e}=4$ ) in the absence of the coupling to the interneuron $\left(g_{\mathrm{GABA}}=\gamma_{i}=0\right)$. The bar graph immediately below shows the number of spikes in 1s time intervals. The right half of panel (a) shows the corresponding information when $\gamma_{i}=0.75$ and $g_{\mathrm{GABA}}=0.25$. Panel (b) shows the same information for the period 5-10s. Panel (c) shows the same information for the period 10-15 s. When the coupling to the interneuron is active, the spiking of the pyramidal cell shows the largest reduction in the first 5 seconds, it remains slower than in the absence of inhibition during the first $15 \mathrm{~s}$, and it does not exceed the firing frequency observed in the absence of inhibition even in later time windows (not shown in the figure).

the beginning of the stimulation. When the interneuron was set to fire at $40 \mathrm{~Hz}\left(J_{I}=0.6\right)$, the firing frequency of the pyramidal cell in this time window (Fig. 3(e)) was lower or at most equal compared to the control condition in which there was no coupling with the interneuron (Fig. 3(d)). Notably, when the interneuron was set to fire at $60 \mathrm{~Hz}\left(J_{I}=1\right)$, the firing frequency of the pyramidal cell was increased 

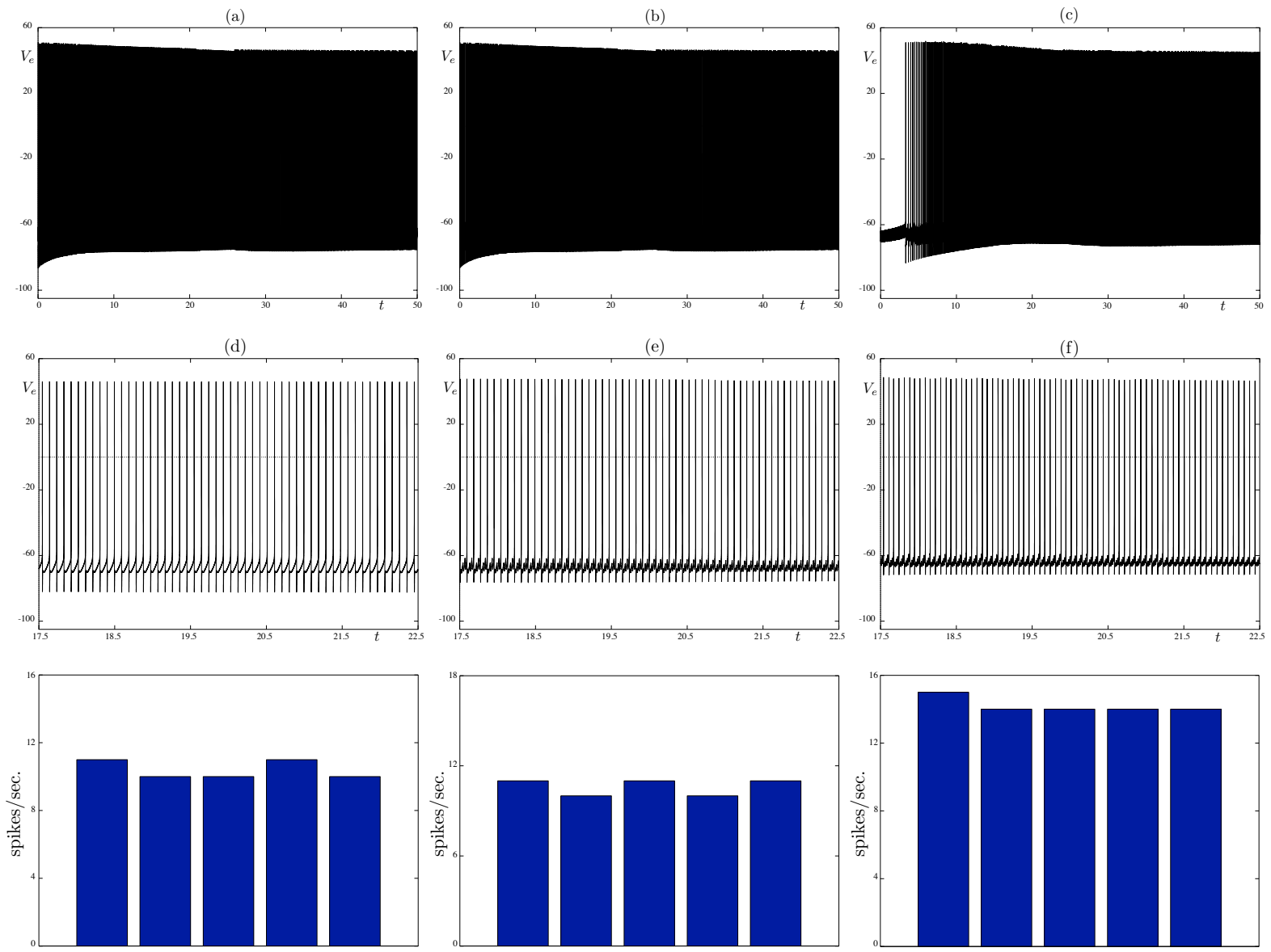

Figure 3: The firing frequency of the interneuron and the potassium efflux that it generates are parameters that can generate different spiking patterns of the pyramidal cell. The panels show the membrane voltage traces of the pyramidal cell with $J_{e}=4$ in different conditions. Panel (a) shows the activity of the pyramidal cell in the absence of the coupling to the interneuron i.e. $g_{\mathrm{GABA}}=\gamma_{i}=0$. Panel (b) shows the activity of the pyramidal cell with $J_{I}=0.6$, which corresponds to the interneuron firing at about $40 \mathrm{~Hz}$. Panel (c) shows hyperexcitability of the pyramidal cell yet no CSD when $J_{I}$ is set to 1 , which corresponds to the interneuron firing at about $60 \mathrm{~Hz}$. Panels (d)-(f) show the zooms of the voltages traces of panels (a), (b) and (c), respectively, in the period 17.5 to $22.5 \mathrm{~s}$ after the beginning of the simulation, in which, for the parameter setting $J_{I}=1$, the firing frequency of the pyramidal cell exceeds its firing frequency observed in the absence of the coupling to the interneuron. The bargraphs indicating the number of spikes in $1 s$ are shown directly below.

(Fig. $3(\mathrm{f})$ ), in comparison with the condition in which there is absence of coupling with the interneuron (Fig. 3(d)). Thus, the increase of the firing frequency of the interneuron can lead in some time windows to increased excitability of the pyramidal cell.

Strikingly, parameter settings leading to high frequency spiking of the interneuron (approximately 80 
(a1)

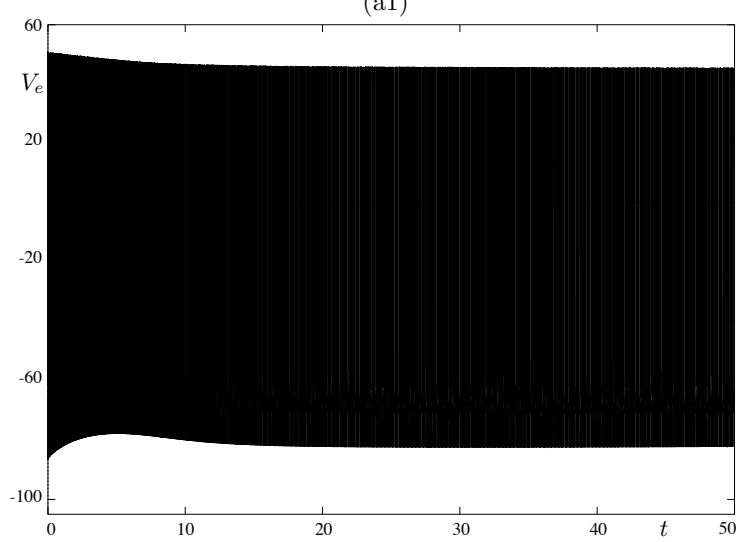

(a2)

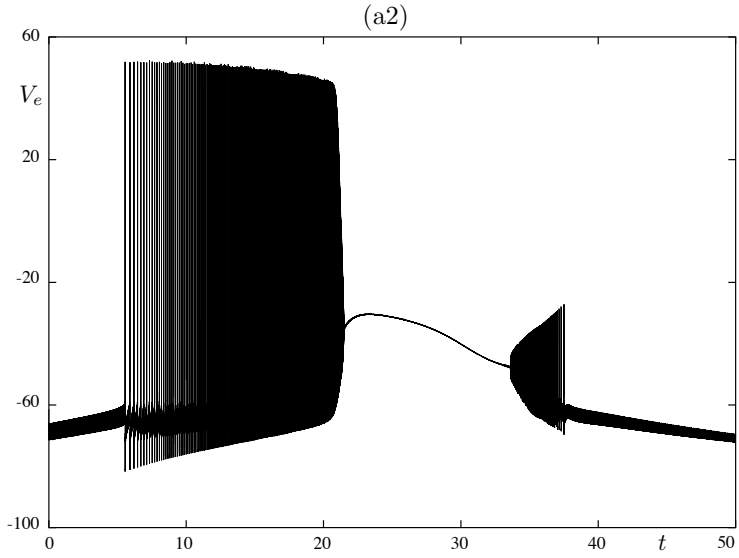

(b1)

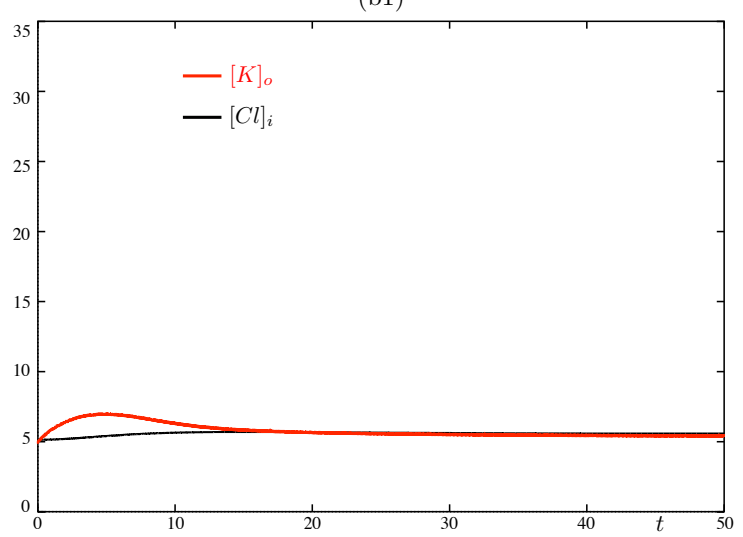

(b2)

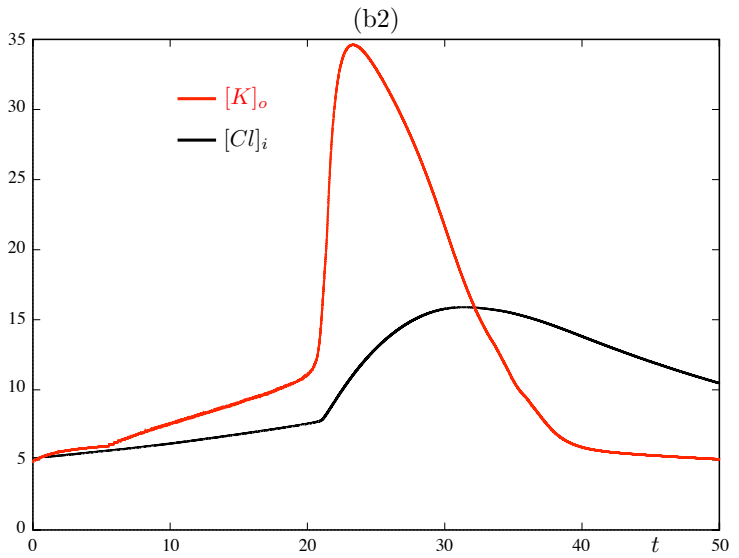

Figure 4: Slow spiking of the pyramidal neuron can turn to spreading depression due to intense interneuron firing that induces extracellular potassium build-up. Panel (a1) shows tonic spiking of the pyramidal cell induced by the excitatory drive $J_{E}=4$ when there is no coupling with the interneuron $\left(g_{\mathrm{GABA}}=0\right.$ and $\left.\gamma_{i}=0\right)$ with the evolution of the extracellular potassium concentration $\left([K]_{o}\right)$ and of the intracellular chloride concentration $([\mathrm{Cl}] \mathrm{i})$ shown in panel (b1). The value of $[\mathrm{Cl}]_{i}$ stays almost constant, close to $5 \mathrm{mM}$. Panel (a2) shows the depolarized block of the pyramidal neuron (CSD) when $g_{\mathrm{GABA}}=0.25$ and $\gamma_{i}=0.75\left(J_{I}=1.2\right.$, corresponding to the interneuron firing at approximately $80 \mathrm{~Hz}$ ). Panel (b2) shows the evolution of $[\mathrm{K}]_{o}$ and $[\mathrm{Cl}]_{i}$ for the same simulation. Note a sharp rise in $[K]_{o}$ from about $10 \mathrm{mM}$ to about $35 \mathrm{mM}$, concurrent with the onset of spreading depression, and a slower increase of $[C l]_{i}$ to about $15 \mathrm{mM}$. The solutions in both simulations have the same initial condition.

Hz: $\left.J_{I}=1.2\right)$ initially abolished the spiking of the pyramidal cell, but subsequently, after a period of intense firing, induced a depolarized block (Fig. 4), which we consider in our model as the initiation of CSD. The onset of CSD was preceded by a significant rise of the extracellular potassium concentration $\left([\mathrm{K}]_{o}\right.$, to about $\left.35 \mathrm{mM}\right)$ and accompanied by a slower increase of the intracellular chloride concentration $\left([\mathrm{Cl}]_{i}\right.$, to about $\left.15 \mathrm{mM}\right)$. In contrast, in the case of the tonic spiking of the pyramidal cell observed when 

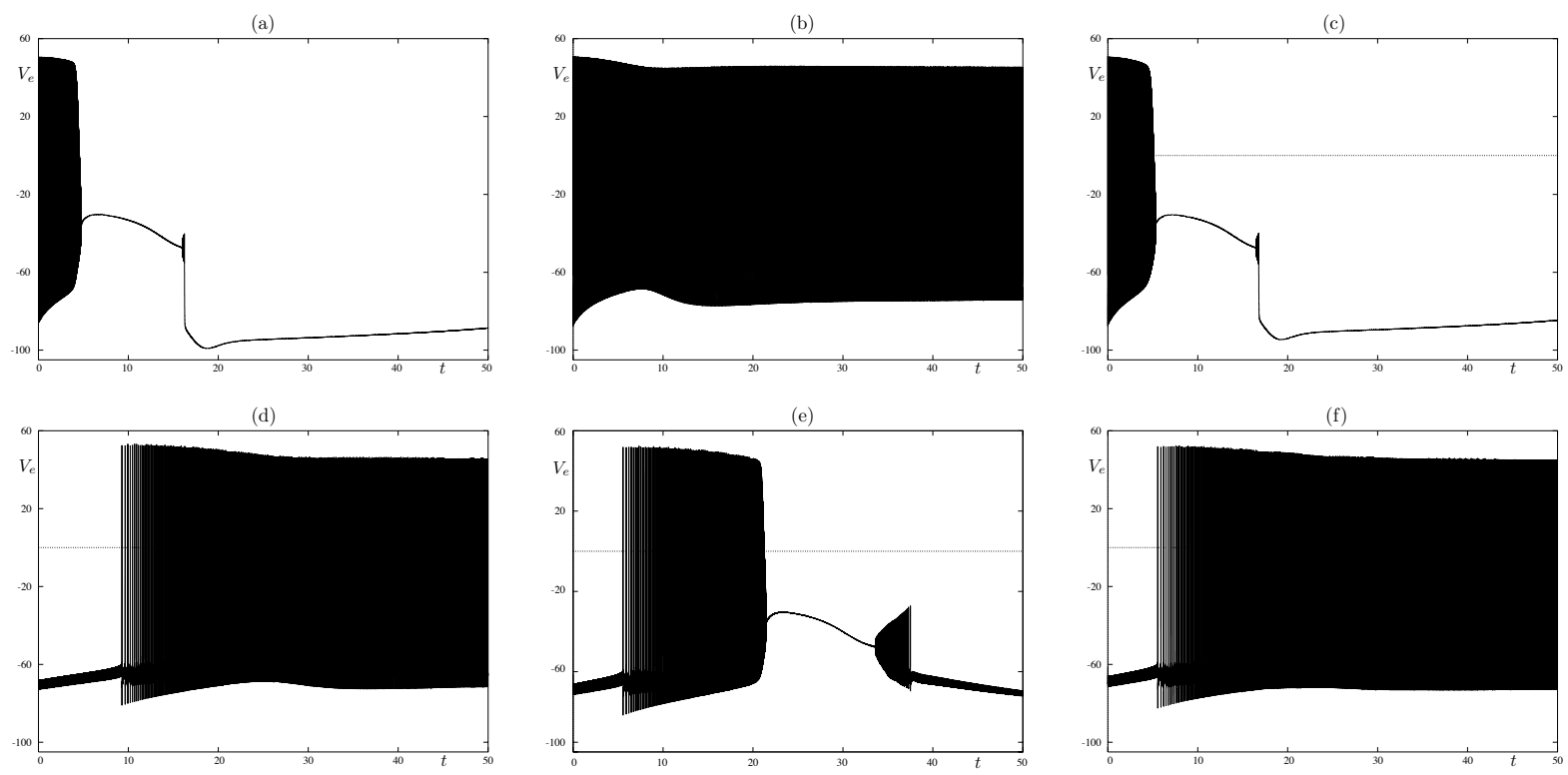

Figure 5: GABAergic transmission delays CSD, whereas potassium build-up and glutamatergic transmission promote CSD. Panel (a) shows CSD for $J_{E}=3.4$, with $g_{\mathrm{AMPA} 1}=g_{\mathrm{AMPA} 2}=0.1, \gamma_{i}=0.75$ and $g_{\mathrm{GABA}}=0$ (block of GABAergic transmission); the depolarized block lasts approximately 13s. Panel (b) shows hyperexcitability but no CSD when $g_{\mathrm{AMPA} 1}$ and $g_{\mathrm{AMPA} 2}$ are set to 0 (block of glutamatergic transmission). Panel (c) shows CSD for $J_{E}=3.7$, with $g_{\mathrm{AMPA} 1}=g_{\mathrm{AMPA} 2}=0$ (block of glutamatergic transmission), $\gamma_{i}=0.75$ and $g_{\mathrm{GABA}}=0$ (block of GABAergic transmission); the depolarized block lasts approximately 13s. Panel (d) shows hyperexcitability but no CSD for $J_{E}=3.7$, with $g_{\mathrm{AMPA} 1}=g_{\mathrm{AMPA} 2}=0.1, \gamma_{i}=0.75$ and $g_{\mathrm{GABA}}=0.25$; the latency to spiking is approximately $10 \mathrm{~s}$. Panel (e) shows CSD for $J_{E}=$, with $g_{\mathrm{AMPA} 1}=g_{\mathrm{AMPA} 2}=0.1, \gamma_{i}=0.75$ and $g_{\mathrm{GABA}}=0.25$; the latency to spiking is approximately $7 \mathrm{~s}$. Panel (f) shows hyperexcitability but no CSD for $J_{E}=4$ when $g_{\mathrm{AMPA} 1}$ and $g_{\mathrm{AMPA} 2}$ are set to 0 ; the latency to spiking is approximately $7 s$.

the coupling with the interneuron was removed (Fig. $4(\mathrm{a} 1)$ ), both $[\mathrm{K}]_{o}$ and $[C l]_{i}$ remained close to $5 \mathrm{mM}$ (Fig. 4(b1)).

\section{Factors that contribute to the onset of CSD}

As shown above, an important factor determining the presence of CSD or hyperexcitability in our model is the baseline current input to the interneuron, $J_{I}$, which controls the firing frequency of the interneuron and the activation of its potassium currents. The key pro-excitatory role of the extracellular potassium build-up generated by the potassium currents of the interneuron is evidenced in Figs. 4 and 6 . These figures show that the onset of CSD is accompanied by a rapid and substantial increase of $[\mathrm{K}]_{o}$ (rising from approximately $10 \mathrm{mM}$ to over $34 \mathrm{mM}$ ).

In another set of simulations we studied the effect of GABAergic and glutamatergic synaptic transmission on CSD onset. We have set the parameters $g_{\mathrm{GABA}}$ and $g_{\mathrm{AMPA}}$ to 0 , exploring different combinations of such settings. Experimentally this would correspond to blocking the GABA and/or AMPA receptors. 
Figure 5 shows a sequence of simulations for increasing values of $J_{E}$ (baseline excitatory drive of the pyramidal cell). For the lowest setting, $J_{E}=3.4$, transition to CSD occurs only if GABA is blocked but AMPA is active $\left(g_{\mathrm{GABA}}=0\right.$ and $\left.g_{\mathrm{AMPA}}=0.1\right)$. This is illustrated in panels (a) and (b) of Figure 5 Increasing excitatory drive to $J_{E}=3.7$ is sufficient for CSD to occur with both GABA and AMPA blocked $\left(g_{\mathrm{GABA}}=g_{\mathrm{AMPA}}=0\right)$. However, if neither GABA nor AMPA are blocked, transition to CSD does not take place $\left(g_{\mathrm{GABA}}=0.2\right.$ and $\left.g_{\mathrm{AMPA}}=0.1\right)$. This is illustrated in panels $(\mathrm{c})$ and $(\mathrm{d})$ of Figure 5 Finally, with $J_{E}=4$, the transition to CSD occurs if neither GABA nor AMPA are blocked $\left(g_{\mathrm{GABA}}=0.25\right.$ and $\left.g_{\mathrm{AMPA}}=0.1\right)$, but it does not occur if AMPA is blocked $\left(g_{\mathrm{AMPA}}=0, g_{\mathrm{GABA}}=0.25\right)$. This is illustrated in panels (e) and (f) of Figure 5.

Overall, our findings show that both glutamate and potassium build-up contribute to the transition to spreading depression in our model, but GABAergic inhibition delays its onset. This suggests that the GABAergic transmission maintains its inhibitory character throughout the process of transition to CSD, and therefore delays it. This conclusion is supported also by the slow increase of $[C l]_{i}$ shown in Fig. 4(b2), which is mainly observed after CSD onset. Conversely, the AMPA-mediated excitation speeds up CSD onset. Nonetheless, it is the activity of the interneuron that, through potassium build-up, leads to CSD.

Besides the classic fast inactivating transient sodium current, neurons show a slowly inactivating "persistent" current $\left(I_{N a p}\right)$, which is important for shaping repetitive firing, generating rhythmicity and amplifying synaptic inputs 28]. $I_{N a p}$ has been found increased in different neurological diseases and it is implicated in some forms of spreading depolarizations 24, 27]; also, some FHM mutations can increase

it 6. 7. We tested the effect of an increase of $I_{N a p}$ maximal conductance in our model. Fig. 6 shows that increasing $I_{N a p}$ leads to a decrease in the latency of CSD.

\section{Transitions to and from CSD seen as dynamic bifurcations}

Both the transition to and from CSD are characterized by rapid changes in the behavior of the variables. Fig. 7 shows the time traces of the membrane potential of the pyramidal neuron $\left(V_{e}\right)$ and of $[\mathrm{K}]_{o}$ shortly before and during the transition to CSD. A remarkable feature is a very fast increase of $[\mathrm{K}]_{o}$ in comparison to its earlier evolution. This can be explained as follows: previously to the onset of CSD there is a temporary balance (a transient steady state) between the effect of the potassium currents of the pyramidal cell and the interneuron (which leads to the increase of $[\mathrm{K}]_{o}$ ), and the homeostatic mechanisms that decrease $[\mathrm{K}]_{o}$ (e.g. the action of the sodium-potassium pump, the extracellular potassium diffusion/glial buffering). As the pyramidal cell firing increases this balance is impaired (the steady state is no longer stable), which results in a rapid increase of $[\mathrm{K}]_{o}$ as well as an average depolarization of the $V_{e}$, leveling off at another transient steady state, which corresponds to CSD; see Fig. 7 panels (a)-(b). In the transition terminating CSD it is only the average value of $V_{e}$ that undergoes a quick change reminiscent of a dynamic bifurcation, whereas $[K]_{o}$ changes gradually, see Fig. 7 panels (c)-(d). Typically the concept of dynamic bifurcation is linked to the presence of multiple time scales, with slow variables seen as dynamic parameters and fast variables undergoing the bifurcations. Remarkably, the simulation in Fig. 7 (b) suggests that $[K]_{o}$ evolves in this stage of the dynamics with comparable speed to the average of Ve, thus that the dynamic bifurcation involves at least these two variables. A similar situation was reported in [10]. By contrast, in the transition that ends CSD, the parameter that undergoes a dynamic bifurcation is the average of Ve. As shown by the simulations of Figure 6, this transition disappears (or is delayed) when the $I_{N a P}$ is increased. 
(a)

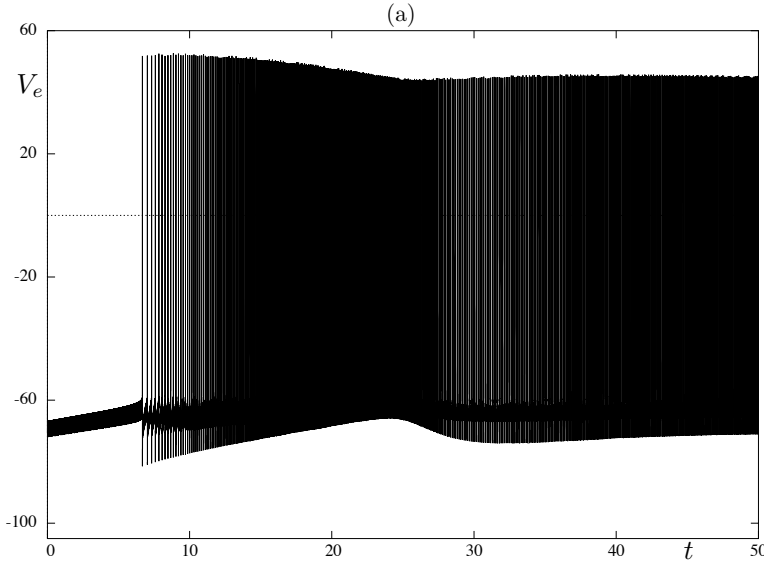

(c)

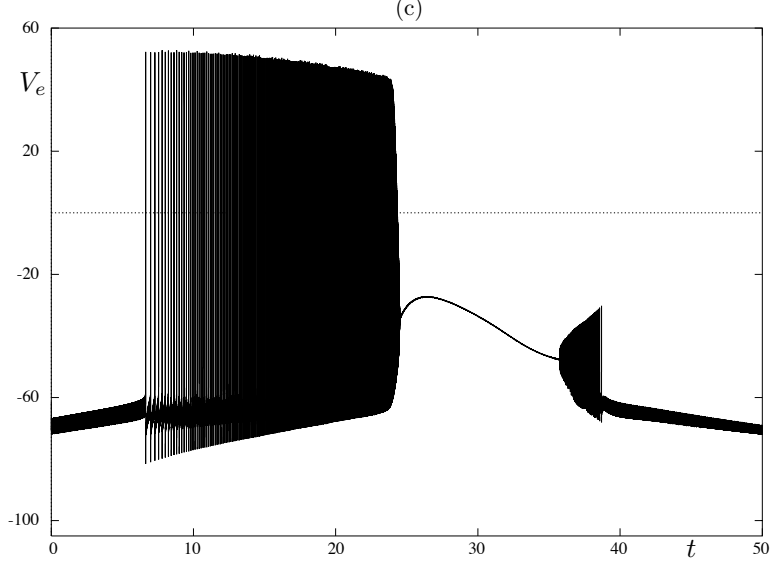

(b)

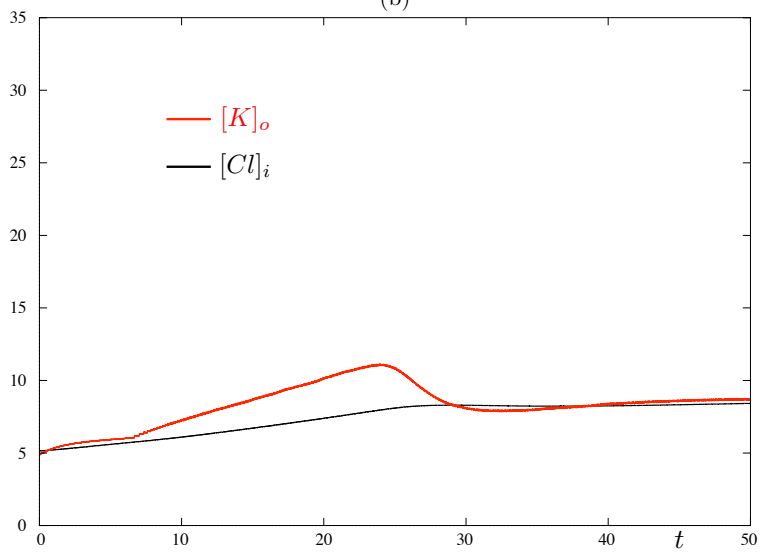

(d)

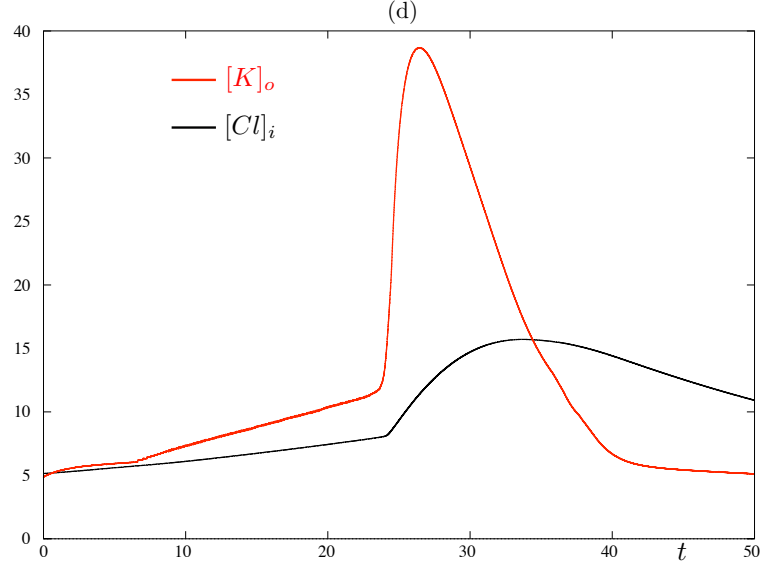

Figure 6: The persistent sodium current $\left(I_{N a p}\right)$ facilitates CSD ignition and prolongs the depolarization. Increasing $I_{N a p}$ by setting $g_{N a p}=2$ has the effect of accelerating CSD and also produces a prolonged depolarization. Panel (a) shows hyperexcitability but no CSD for $g_{N a p}=0.5, J_{E}=3.9$, with $g_{\mathrm{AMPA} 1}=g_{\mathrm{AMPA} 2}=0.1, \gamma_{i}=0.75$ and $g_{\mathrm{GABA}}=0.25$. Panel $(\mathrm{b})$ shows the corresponding potassium and chloride dynamics. Increasing $g_{N a p}$ to 2 (panel c) results in CSD. Note that latency to spiking in panels (a) and (c) is the same (about $7 s$ ). The length of the depolarizing block is about $13 s$, approximately as in the case of Figure 4(a2) $\left(J_{E}=4, I_{N a p}=0.5\right)$. Panel (d) shows the corresponding potassium and chloride dynamics, with the potassium peak higher than in the case of Figure 4 $(\mathrm{b} 2)\left(J_{E}=4, I_{N a p}=0.5\right)$, reaching $40 \mathrm{mM}$, as opposed to $35 \mathrm{mM}$. The latency to spiking is approximately $7 s$ in both cases ( $I_{N a p}$ activates close to the spiking threshold), but in the case of $g_{N a p}=2$ the extracellular potassium rises faster, leading to CSD.

\section{Discussion}

In this work we have developed and studied a model of a cortical microcircuit consisting of two coupled neurons, a pyramidal cell and a GABAergic interneuron, and diffusion of potassium in the extracellular 
(a)

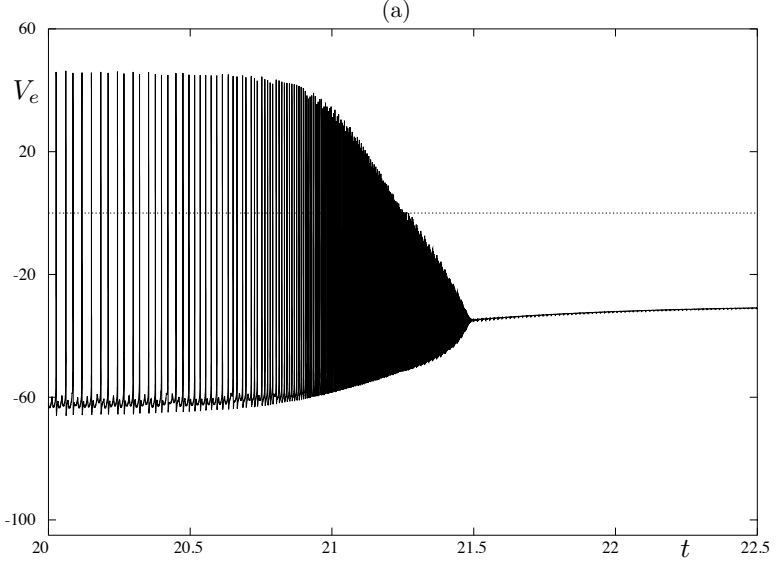

(c)

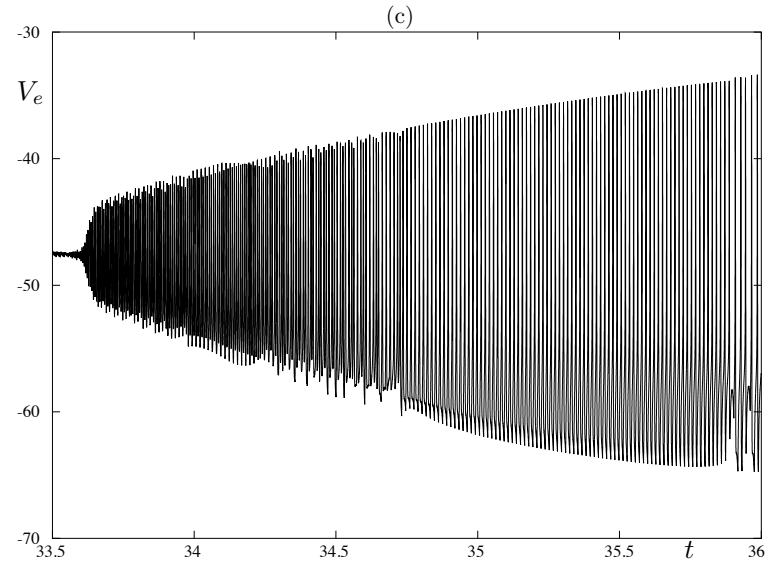

(b)

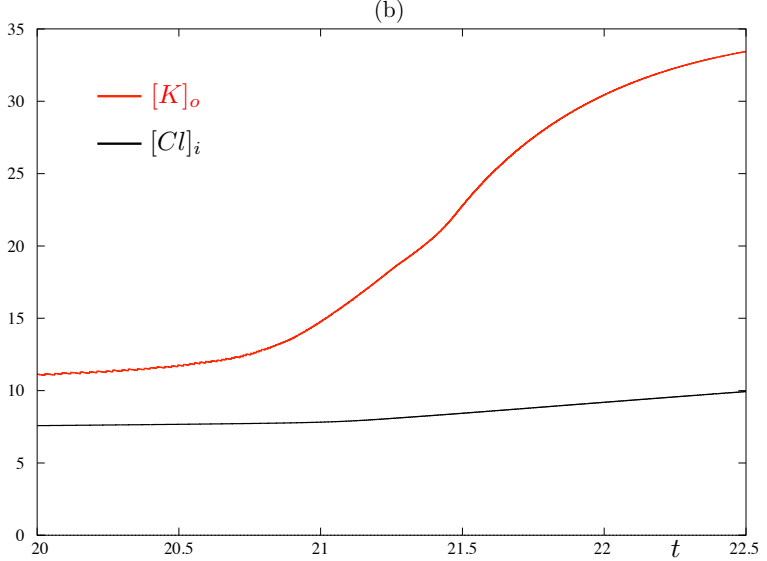

(d)

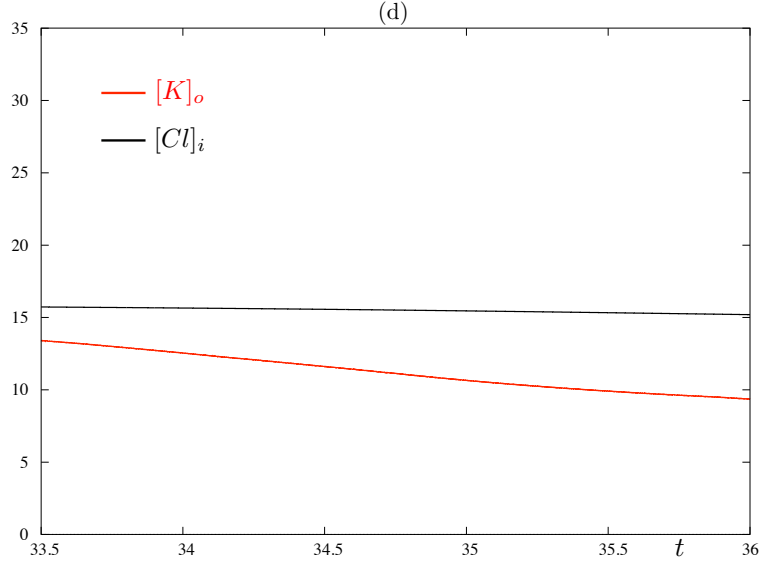

Figure 7: Transitions to and from CSD as dynamic bifurcations. The figures represent zooms of Fig. 4 (a2) and Fig. 4 (b2) corresponding to different time intervals $\left(J_{E}=4, g_{\mathrm{GABA}}=0.25, \gamma_{i}=0.75\right.$, $g_{\mathrm{AMPA} 1}=g_{\mathrm{AMPA} 2}=0.1$ and $J_{I}=1.2$ ). Panel (a) shows the time trace of the membrane potential of the pyramidal cell $\left(V_{e}\right)$ directly before and during CSD. Note that the average of Ve is almost constant in the initial 2 seconds and grows quickly to a different level in the subsequent 2 seconds. Panel (b) shows a similar phenomenon for $[K]_{o}$. Panel (c) shows a transition that ends CSD, with the average of Ve sharply dropping. Panel (d) shows that $[K]_{o}$ changes uniformly during the transition ending CSD.

space. The coupling, in addition to the usual synaptic transmission, included the depolarizing effect of the potassium efflux due to the spiking of the interneuron and of the pyramidal cell. The pyramidal cell, besides the ion channels involved in the generation of action potentials, includes KCC2 and NKCC1 transporters implicated in intracellular chloride homeostasis. We used this model to test the hypothesis that hyperexcitability of GABAergic cortical neurons can lead to CSD, a possible pathological mechanism of migraine with aura $13,20,27]$. This hypothesis has been proposed because migraine mutations of the 
NaV1.1 sodium channel, which is particularly important for the excitability of GABAergic interneurons, can induce gain of function of the channel and hyperexcitability in transfected cells [5 7]. However, the hypothesis has not been tested yet in a neuronal circuit and the detailed mechanism has not been addressed.

Our work shows that CSD can be ignited by high frequency spiking of the interneuron in our model. More generally, we have observed three possible effects of the interneuron on the firing of the pyramidal cell, depending on the interneuron's firing frequency. For low frequencies, the effect was inhibitory in the initial 5-10 s and in the subsequent periods of the simulation the firing frequency was not increased. For higher frequencies, the activity of the interneuron increased the firing frequency of the pyramidal cell in a time window of the simulation. If the frequency of the interneuron was sufficiently high, a transition to CSD took place. Importantly, when the potassium build up caused by the interneuron firing was not taken into account, the interneuron had always an inhibitory effect, even when it fired at high frequency.

Dynamic bifurcations, typical of slow-fast systems, are characterized by rapid changes of the fast variables. Although we are aware of the presence of multiple timescales in our system, time scale separation is not explicit. Our simulations suggest that $[K]_{o}$ and the average of the membrane potential evolve on the same time scale, at least during the transition to CSD. Proper identification of the underlying slow-fast structure and the type of bifurcation that occurs could lead to a method of predicting how close the system is to the transition to CSD and whether the transition will happen or not for the given parameter set. Partial and somewhat inconsistent bifurcation pictures of CSD models were obtained in 36 and 39, which used systems that were similar, although not identical, to the one that we have used. In particular our main bifurcation parameter is the excitatory drive to the interneuron, which determines its firing frequency and that differs from both of these studies. Consequently, we feel that there is a need for an additional bifurcation study. Often a useful approach is to design a minimal system (a 'toy model') with similar dynamics but simple enough so that the bifurcation structure can be clearly identified. This will be the subject of future work.

Another follow-up of our study would be to consider a network model, including, in addition to $[K]_{o}$ diffusion, also long distance excitatory projections onto both pyramidal cells and interneurons, and glial spatial buffering of potassium, which may play a role in the context of a realistic network. Interesting questions are the minimal number of hyperexcitable GABAergic interneurons that are necessary for igniting a propagating CSD, and if there are conditions (parameter settings) for which CSD would be ignited but does not propagate (remains localized). These issues are important because long lasting high frequency firing of large populations of interneurons is not a common phenomenon. This has been proposed as the mechanism of some types of focal seizures 1], but for CSD ignition and propagation the interneuron population has probably to be larger. Migraine attacks, as epileptic seizures, are characterized by acute and transient presentation of symptoms in individuals that otherwise appear normal; migraine can be triggered by emotional, dietary or physical stimuli 13 27. Thus, a trigger stimulus could amplify a local event and induce large scale hyperexcitability of GABAergic interneurons leading to propagation of CSD. Interestingly, interneurons' excitability can be regulated by neuromodulators and hormones 14 .

Our work contributes to show that interneuron hyperexcitability can be the pathological mechanism of FHM-3, consistently with the hypothesis proposed studying the functional effect of FHM-3 NaV1.1 mutations in transfected cells, and it poses a more general question about the role of interneurons in migraine with aura. Possibly, dysfunctions leading to GABAergic interneurons' hyperexcitability (not limited to NaV1.1) could be a more general group of pathological mechanisms in migraine with aura, which is probably characterized by numerous different mechanisms, as suggested by the different mechanisms already identified in the rare FHM phenotype. Thus, our study suggests that hyperexcitability of interneuron populations could play a critical role in CSD ignition, even if they are not its sole cause. 
Understanding these mechanisms in detail could lead to pharmacological advances in the treatment of migraine.

\section{Funding}

European Union projects DESIRE (grant n. EFP7-602531 to MM) and Investissements d'AvenirLaboratory of Excellence "Ion Channels Science and Therapeutics" (grant LabEx ICST ANR-11-LABX0015-01 to MM). ERC Advanced Grant Nervi 227747 (to OF).

\section{References}

[1] Avoli M, de Curtis M (2011) GABAergic synchronization in the limbic system and its role in the generation of epileptiform activity. Prog Neurobiol 95: 104-132.

[2] Börgers C, Epstein S, Kopell N (2005) Background gamma rhythmicity and attention in cortical local circuits: A computational study. Proc Natl Acad Sci USA 102: 7002-7007.

[3] Capuani C, Melone M, Tottene A, Bragina L, Crivellaro G, Santello M, Casari G, Conti F, Pietrobon, $\mathrm{D}$ (2016) Defective glutamate and $\mathrm{K}^{+}$clearance by cortical astrocytes in familial hemiplegic migraine type 2. EMBO Mol Med e201505944.

[4] Cestele S, Scalmani P, Rusconi R, Terragni B, Franceschetti S, Mantegazza M (2008) Self-limited hyperexcitability: functional effect of a familial hemiplegic migraine mutation of the Nav1. 1 (SCN1A) $\mathrm{Na}^{+}$channel. J. Neurosci. 28: 7273-7283.

[5] Cestèle S, Labate A, Rusconi R, Tarantino P, Mumoli L, Franceschetti S, Annesi G, Mantegazza M, Gambardella A (2013) Divergent effects of the T1174S SCN1A mutation associated with seizures and hemiplegic migraine. Epilepsia 54: 927-935.

[6] Cestèle S, Schiavon E, Rusconi R, Franceschetti S, Mantegazza M (2013) Nonfunctional $\mathrm{Na}_{\mathrm{v}} 1.1$ familial hemiplegic migraine mutant transformed into gain of function by partial rescue of folding defects. Proc Natl Acad Sci USA 110: 17546-17551.

[7] De Fusco M, Marconi R, Silvestri L, Atorino L, Rampoldi L, Morgante L, Ballabio A, Aridon P, Casari G (2003) Haploinsufficiency of ATP1A2 encoding the $\mathrm{Na}^{+} / \mathrm{K}^{+}$pump 2 subunit associated with familial hemiplegic migraine type 2. Nat Gen 33:192-196.

[8] Dichgans M, Freilinger T, Eckstein G, Babini E, Lorenz-Depiereux B, Biskup S, Ferrari MD, Herzog J, van den Maagdenberg AM, Pusch M, Strom TM (2005) Mutation in the neuronal voltage-gated sodium channel SCN1A in familial hemiplegic migraine. Lancet 366: 371-377.

[9] Doyon N, Prescott SA, Castonguay A, Godin AG, Kröger H, De Koninck Y (2011) Efficacy of synaptic inhibition depends on multiple, dynamically interacting mechanisms implicated in chloride homeostasis. PLoS Comput Biol 7: e1002149.

[10] Dreier JP (2011) The role of spreading depression, spreading depolarization and spreading ischemia in neurological disease. Nat Med 17: 439-447. 
[11] Ermentrout B (2002) Simulating, analyzing, and animating dynamical systems: a guide to XPPAUT for researchers and students. SIAM.

[12] Ferrari MD, Klever RR, Terwindt GM, Ayata C and van den Maagdenberg AM (2015) Migraine pathophysiology: lessons from mouse models and human genetics. Lancet Neurol 14: 65-80.

[13] Freund TF, Katona I (2007) Perisomatic inhibition. Neuron 56: 33-42.

[14] Guerrini R, Marini C, Mantegazza M (2014) Genetic Epilepsy Syndromes Without Structural Brain Abnormalities: Clinical Features and Experimental Models. Neurotherapeutics 11: 269-285.

[15] Han S, Tai C, Westenbroek RE, Yu FH, Cheah CS, Potter GB, Rubenstein JL, Scheuer T, de la Iglesia HO, Catterall WA (2012) Autistic-like behaviour in Scn1a ${ }^{+/-}$mice and rescue by enhanced GABA-mediated neurotransmission. Nat 489: 385-390.

[16] Hedrich UB, Liautard C, Kirschenbaum D, Pofahl M, Lavigne J, Liu Y, Theiss S, Slotta J, Escayg A, Dihne M, Beck H, Mantegazza M, Lerche H (2014) Impaired action potential initiation in GABAergic interneurons causes hyperexcitable networks in an epileptic mouse model carrying a human $\mathrm{Na}(\mathrm{V}) 1.1$ mutation. J Neurosci 34: 14874-14889.

[17] Kahlig KM, Rhodes TM, Pusch M, Freilinger T, Pereira-Monteiro JM, Ferrari MD, van den Maagdenberg AM, Dichgans M, George AL Jr (2008) Divergent sodium channel defects in familial hemiplegic migraine. Proc Natl Acad Sci USA 105: 9799-9804.

[18] Kaila K, Price TJ, Payne JA, Puskarjov M, Voipio J (2014) Cation-chloride cotransporters in neuronal development, plasticity and disease. Nat Rev Neurosci 15: 637-654.

[19] Lauritzen M. (1994) Pathophysiology of the migraine aura. The spreading depression theory. Brain 117: 199-210.

[20] Leo L, Gherardini L, Barone V, De Fusco M, Pietrobon D, Pizzorusso T, Casari G (2011) Increased susceptibility to cortical spreading depression in the mouse model of familial hemiplegic migraine type 2. PLoS Genet 7: e1002129.

[21] Lillis KP, Kramer MA, Mertz J, Staley KJ, White JA (2012) Pyramidal cells accumulate chloride at seizure onset. Neurobiol Dis 47: 358-366.

[22] van den Maagdenberg AM, Pietrobon D, Pizzorusso T, Kaja S, Broos LA, Cesetti T, van de Ven RC, Tottene A, van der KJ, Plomp JJ, Frants RR, Ferrari MD (2004) A Cacna1a knockin migraine mouse model with increased susceptibility to cortical spreading depression. Neuron 41: 701-710.

[23] Mantegazza M, Curia G, Biagini G, Ragsdale DS, Avoli M (2010) Voltage-gated sodium channels as therapeutic targets in epilepsy and other neurological disorders. Lancet Neurol 9: 413-424.

[24] Ogiwara I, Miyamoto H, Morita N, Atapour N, Mazaki E, Inoue I, Takeuchi T, Itohara S, Yanagawa Y, Obata K, Furuichi T, Hensch TK, Yamakawa K (2007) Na(v)1.1 localizes to axons of parvalbuminpositive inhibitory interneurons: a circuit basis for epileptic seizures in mice carrying an Scn1a gene mutation. J Neurosci 27: 5903-5914. 
[25] Ophoff RA, Terwindt GM, Vergouwe MN, van Eijk R, Oefner PJ, Hoffman SM, Lamerdin JE, Mohrenweiser HW, Bulman DE, Ferrari M, Haan J, Lindhout D, van Ommen GJ, Hofker MH, Ferrari MD, Frants RR (1996) Familial hemiplegic migraine and episodic ataxia type-2 are caused by mutations in the Ca2+ channel gene CACNL1A4. Cell 87: 543-552.

[26] Pietrobon D, Moskowitz M (2014) Chaos and commotion in the wake of cortical spreading depression and spreading depolarizations. Nature Rev Neurosci 15: 379-392.

[27] Stafstrom CE (2007) Persistent sodium current and its role in epilepsy. Epilepsy Curr 7: 15-22.

[28] Syková E, Nicholson C (2008) Diffusion in brain extracellular space. Physiol Rev 88: 1277-1340.

[29] Tottene A, Conti R, Fabbro A, Vecchia D, Shapovalova M, Santello M, van den Maagdenberg AM, Ferrari MD, Pietrobon D (2009) Enhanced excitatory transmission at cortical synapses as the basis for facilitated spreading depression in $\mathrm{Ca}(\mathrm{v}) 2.1$ knockin migraine mice. Neuron 61: 762-773.

[30] Traub RD, Wong RK, Miles R and Michelson H (1991) A model of a CA3 hippocampal pyramidal neuron incorporating voltage-clamp data on intrinsic conductances. J Neurophysiol 66: 635-650.

[31] Ullah G, Wei Y, Dahlem MA, Wechselberger M and Schiff SJ (2015) The Role of Cell Volume in the Dynamics of Seizure, Spreading Depression, and Anoxic Depolarization. PLoS Comput Biol 11: e1004414.

[32] Vecchia D, Pietrobon D (2012) Migraine: a disorder of brain excitatory-inhibitory balance? Trends in Neurosci 35: 507-520.

[33] Vecchia D, Tottene A, van den Maagdenberg AM, Pietrobon D (2014) Mechanism underlying unaltered cortical inhibitory synaptic transmission in contrast with enhanced excitatory transmission in Ca2.1 knockin migraine mice. Neurobiol Dis 69: 225-234.

[34] Viitanen T, Ruusuvuori E, Kaila K, Voipio J (2010) The K+-Cl cotransporter KCC2 promotes GABAergic excitation in the mature rat hippocampus. J Physiol 588: 1527-1540.

[35] Wei Y, Ullah G, Schiff SJ (2014) Unification of neuronal spikes, seizures, and spreading depression. J Neurosci 34: 11733-11743.

[36] Wang XJ, Buzsáki G (1996) Gamma oscillation by synaptic inhibition in a hippocampal interneuronal network model. J Neurosci 16: 6402-6413.

[37] Yu FH, Mantegazza M, Westenbroek RE, Robbins CA, Kalume F, Burton KA, Spain WJ, McKnight GS, Scheuer T, Catterall WA (2006) Reduced sodium current in GABAergic interneurons in a mouse model of severe myoclonic epilepsy in infancy. Nat Neurosci 9: 1142-1149.

[38] Zandt BJ, ten Haken B, van Putten MJ, Dahlem MA (2015) How does spreading depression spread? Physiology and modeling. Rev Neurosci 26: 183-198. 